Article

\title{
CuZnZr-Zeolite Hybrid Grains for DME Synthesis: New Evidence on the Role of Metal-Acidic Features on the Methanol Conversion Step
}

\author{
Massimo Migliori ${ }^{1, *(\mathbb{C})}$, Antonio Condello ${ }^{1}$, Francesco Dalena ${ }^{1}$, Enrico Catizzone ${ }^{2}(\mathbb{D})$ and \\ Girolamo Giordano ${ }^{3}$ \\ 1 Department of Environmental Engineering, University of Calabria, Via P., Bucci-I-87036 Rende (CS), Italy; \\ antoniocondello@gmail.com (A.C.); francesco.dalena@unical.it (F.D.) \\ 2 ENEA, Italian National Agency for New Technologies, Energy and Sustainable Economic Development, \\ Trisaia Research Centre, MT I-75026 Rotondela, Italy; enrico.catizzone@enea.it \\ 3 ERIC Aisbl, University of Calabria, Via P., Bucci-I-87036 Rende (CS), Italy; ggiordaunical@yahoo.it \\ * Correspondence: massimo.migliori@unical.it; Tel.: +39-0984-496641
}

Received: 22 February 2020; Accepted: 11 June 2020; Published: 15 June 2020

\begin{abstract}
The assessment of the catalytic performance of "hybrid" metal/zeolite catalysts (based on FER or MFI structure and CuZnZr metal complexes) in the methanol dehydration step to DME has been studied in this work. The results clearly show that there is an important effect of the interaction between metal and acid sites affecting the acid catalyst performances. Additionally, deactivation, studied by means of a Timo-on-Stream (TOS) test, was affected by the type of zeolite structure used for hybrid catalyst preparation. The decrease in DME selectivity can be attributed to the cooperation of metal and acid sites in the production of different compounds (mainly methyl formate and dimethoxy methane) converting methanol and DME. The presence of these compounds (indicating different reaction pathways active) was found to be dependent on the zeolite structure and on the type of co-precipitation medium (water or ethanol) used to prepare the hybrid catalyst.
\end{abstract}

Keywords: methanol; zeolite; hybrid catalyst; selectivity; conversion

\section{Introduction}

DME is a colorless, non-toxic, non-corrosive organic compound that is receiving a renewed attention as alternative fuel for diesel engines [1] thanks to its high cetane number (55-60) and its low emissions of fine particles and $\mathrm{NO}_{x}$ [2]. In recent decades, in fact, the consumption of DME as an alternative fuel to Liquified Petroleum Gas (LPG) or mixed with the latter has increased considerably. One of the DME production processes that is receiving increasing attention, especially for the reduction of green-house emission, is the "one pot" hydrogenation of $\mathrm{CO}_{2}$ by using a "hybrid catalyst" obtained through the combination of an acid catalyst (typically zeolite due to its resistance to deactivation against water [3]) with a redox catalyst [4]. Previous studies have shown the catalytic and adsorption performances of the micro and mesoporous materials drastically change in the presence of metals $[5,6]$. A great variety of catalysts have been studied for $\mathrm{CO}_{2}$ hydrogenation, paying attention to the metallic phase role and characteristics: $\mathrm{Cu}-\mathrm{ZnO}[7-9], \mathrm{Pd}[10,11]$ and other bimetallic catalysts [12]. $\mathrm{Cu}-\mathrm{ZnO}$-based catalysts are the most assessed $[13,14]$, and the addition of various promoter/carrier oxides to the $\mathrm{Cu}-\mathrm{ZnO}$ couple has been widely investigated [15-17]. Zirconia was found to be a promising promoter, and $\mathrm{Cu}-\mathrm{ZnO}-\mathrm{ZrO}_{2}$ catalysts have been investigated in combination with acidic functions of zeolites for the "one pot" production of DME [18-22]. A comprehensive study of the direct hydrogenation of $\mathrm{CO} 2$ to DME is reported in ref [23]. In particular, CuZnZr/FER hybrid grain prepared by oxalate co-precipitation of metal precursors over zeolite crystals is considered a very active 
multifunctional catalyst in terms of $\mathrm{CO}_{2}$ conversion and DME selectivity [22,24-26]. Nevertheless, a marked catalyst deactivation was observed. Neither hydrocarbon or coke formation nor metal sintering seems to be the cause of the observed deactivation [21], whereas an exchange of acidic sites of zeolites by $\mathrm{Cu}^{2+}$ ions seems to be one of the most credited hypotheses [26]. In this regard, it is interesting to focus attention on the metal-acidic function interaction. This could contribute to better elucidating the real deactivation mechanism, opening new perspectives on the wider diffusion of those hybrid catalysts in DME direct synthesis from $\mathrm{CO}_{2}$ hydrogenation. The aim of this study is to investigate the effect of metal deposition on the acidic function of the zeolite-based catalyst during the methanol dehydration step. To this end, several $\mathrm{CuZnZr} /$ zeolite hybrid catalysts were prepared by using two types of zeolite structures, namely MFI and FER. The metal redox function was induced in the sample by the gel-oxalate co-precipitation preparation method, and the effect of different co-precipitation media was also assessed.

\section{Results}

\subsection{Samples Preparation and Nomenclature}

MFI and FER zeolites were prepared by hydrothermal crystallization starting from synthesis gel with a Si/Al molar ratio equals to 25 and 10, respectively. More details about the synthesis procedure have been reported in previous works $[3,27]$. From now on, the obtained protonic form zeolites with MFI and FER structure will be called P_ZSM5 and P_FER, respectively.

Hybrid samples were obtained by gel oxalate coprecipitation [21] of the $\mathrm{Cu}, \mathrm{Zn}$, and $\mathrm{Zr}$ precursor in nitrate form. The metal precursors were added to obtain a final atomic ratio to $60 / 30 / 10(\mathrm{Cu} / \mathrm{Zn} / \mathrm{Zr})$ while the $\mathrm{CuZnZr} /$ zeolite weight ratio was set at 1 . The metal precursors were added dropwise to the solution of oxalic acid, zeolite and ethanol and stirred for $60 \mathrm{~min}$, and then ultrasound treated for $30 \mathrm{~min}$ to promote the precipitation of the solid phase overnight. To verify whether the medium can somehow influence the catalytic activity of the samples, MFI-based catalyst was also prepared by replacing ethanol with distilled water as a co-precipitation medium.

The solid phase was recovered, washed with distilled water, and dried at $80^{\circ} \mathrm{C}$. Finally, the solid was subjected to calcination up to $350^{\circ} \mathrm{C}$ with the following steps: $1 \mathrm{~h}$ up to $100{ }^{\circ} \mathrm{C}, 1 \mathrm{~h}$ up to $200{ }^{\circ} \mathrm{C}, 1 \mathrm{~h}$ up to $350{ }^{\circ} \mathrm{C}$, static at $350{ }^{\circ} \mathrm{C}$ for $4 \mathrm{~h}$. For each heating step, a rate of $2{ }^{\circ} \mathrm{C} / \mathrm{min}$ was adopted. The obtained samples were labeled as $\mathrm{M} \_Z e o \_X$, where $\mathrm{M}$ indicates the presence of metals, Zeo indicates the zeolite type (FER or ZSM5) and X indicates the solvent used during co-precipitation (W stands for water and A for Alcohol, i.e., ethanol). The sample M_FER_A was the only one already fully characterized and catalytically assessed in previously published papers [21,22].

\subsection{Structural Analysis}

The X-ray diffraction (XRD) analysis of all the samples revealed a good crystallinity, and no other phases or amorphous were identified in the parent samples (Figure S1 of Supplementary Materials). When compared with the parent forms, the samples M_ZSM5_W and M_FER_W showed a significant intensity, even though the effect of metal deposition was clearly visible [22].

Scanning Electron Microscopy (SEM) analysis of the parent samples (Figure 1) revealed the typical prism shape of MFI-type zeolite (approximate dimensions $11 \mu \mathrm{m}$ in length, $8 \mu \mathrm{m}$ in width and $5 \mu \mathrm{m}$ in thickness); FER zeolite also showed the typical form, with the typical lamellar two-dimensional shape [28]. A random distribution of metal clusters was observed for hybrid samples. 

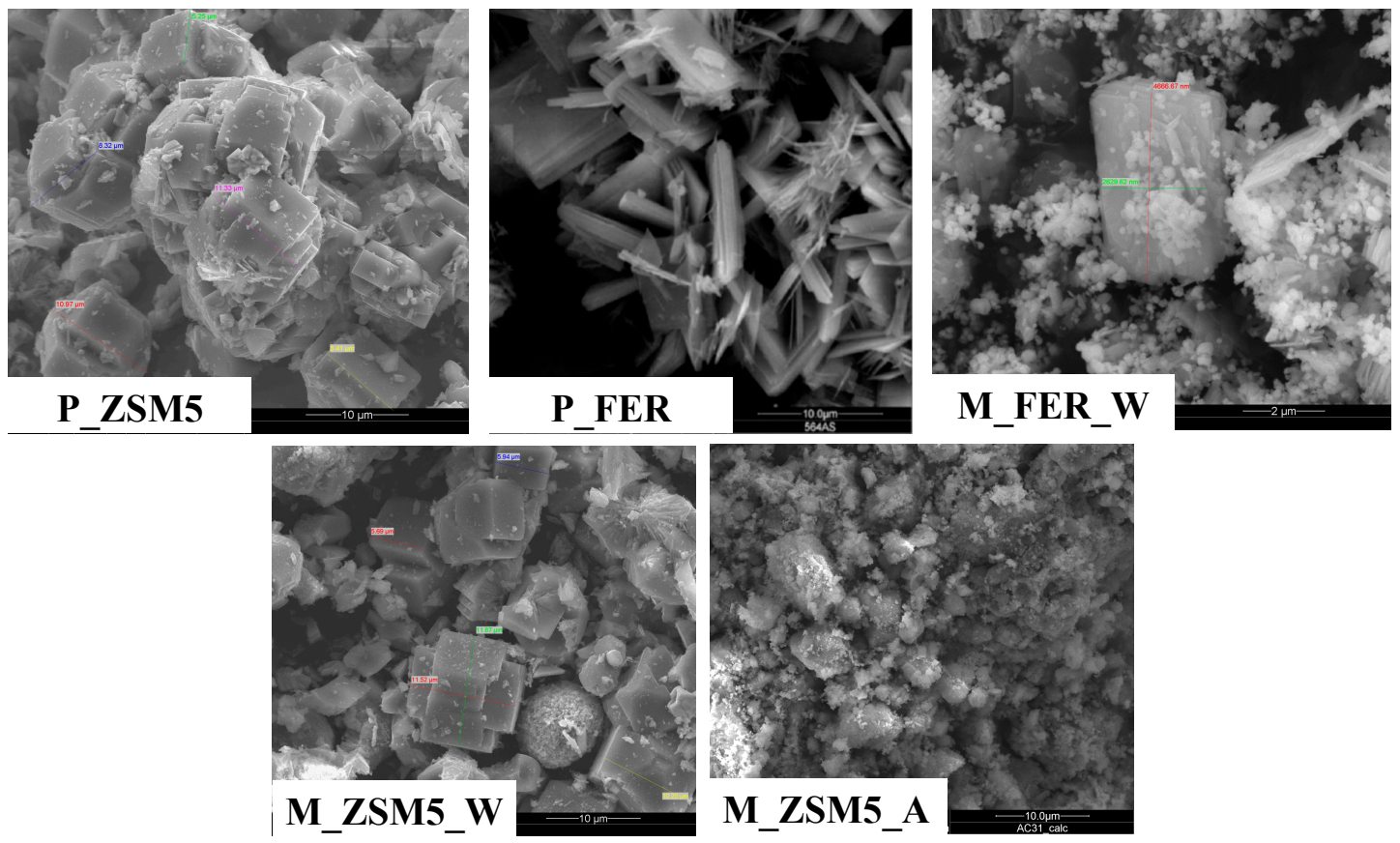

Figure 1. SEM images for parent and hybrid samples.

Table 1 summarizes the nitrogen adsorption isotherms at $-196{ }^{\circ} \mathrm{C}$ of all the catalysts analyzed in this work (data plot in Figures S2 and S3 of Supplementary Materials). The addition of metals in zeolite clearly causes a reduction in both specific surface area and in micropore volume and area. Mesopore volume, estimated by difference between total and micropore volumes, seems to be unaffected by metal deposition in the case water is used as co-precipitation medium. On the contrary, the mesopore volume of M_ZSM5_A is two-fold higher than both P_ZSM-5 and M-ZSM-W, suggesting a key role of co-precipitation medium on metal phase structure.

Table 1. Textural properties of parent and hybrid samples.

\begin{tabular}{cccccc}
\hline Sample & $\begin{array}{c}\text { Specific } \\
\text { Surface Area } \\
\text { (B.E.T.) }\left[\mathbf{m}^{2} / \mathbf{g}\right]\end{array}$ & $\begin{array}{c}\text { Micropore } \\
\text { Area } \\
{\left[\mathbf{m}^{2} / \mathbf{g}\right]}\end{array}$ & $\begin{array}{c}\text { External Surface } \\
\text { Area } \\
{\left[\mathbf{m}^{2} / \mathbf{g}\right]}\end{array}$ & $\begin{array}{c}\text { Pore } \\
\text { Volume } \\
{\left[\mathbf{c m}^{3} / \mathbf{g}\right]}\end{array}$ & $\begin{array}{c}\text { Micropore } \\
\text { Volume } \\
{\left[\mathbf{c m}^{3} / \mathbf{g}\right]}\end{array}$ \\
\hline P_FER & 329 & 291 & 48 & 0.226 & 0.136 \\
P_ZSM5 & 360 & 211 & 149 & 0.194 & 0.094 \\
M_ZSM5_W & 218 & 132 & 87 & 0.184 & 0.061 \\
M_ZSM5_A & 229 & 127 & 101 & 0.271 & 0.059 \\
M_FER_W & 185 & 153 & 32 & 0.156 & 0.071 \\
M_FER_A ${ }^{\text {a }}$ & 182 & 151 & 31 & 0.335 & 0.038 \\
\hline
\end{tabular}

The chemical analysis data (Table 2) show that the Si/Al ratio increases slightly after metal co-precipitation, which may be due to partial aluminum leaching. For all the hybrid samples, the $\mathrm{Cu} / \mathrm{Zn}$ atomic is similar to the theoretical one, namely 2.

The overall concentration of the acid sites of the investigated samples is reported in Table 3, and the acid sites strength was classified according to ammonia desorption temperature (see data in Figure S4 of Supplementary Materials); the sites desorbed in the temperature range $150-325^{\circ} \mathrm{C}$ and above $325^{\circ} \mathrm{C}$ were labelled as weak and strong acid sites, respectively. P_FER possesses a higher total acid site concentration than P_ZSM5, according to the Si/Al ratio. Furthermore, stronger acid sites seem to be present on $\mathrm{P}_{\text {_FER, }}$, since a higher maximum desorption temperature $\left(556{ }^{\circ} \mathrm{C}\right)$ with respect to P_ZSM5 $\left(455^{\circ} \mathrm{C}\right)$ was measured. 
Table 2. Chemical composition of parent and hybrid samples.

\begin{tabular}{cccc}
\hline Sample & $\begin{array}{c}\text { Si/Al } \\
{[\mathbf{m o l} / \mathbf{m o l}]}\end{array}$ & $\begin{array}{c}\text { Cu/Zn } \\
{[\mathbf{m o l} / \mathbf{m o l}]}\end{array}$ & $\begin{array}{c}\text { CZZ/Zeolite } \\
{[\mathbf{w} / \mathbf{w}]}\end{array}$ \\
\hline P_FER & 8.6 & - & - \\
P_ZSM5 & 18.7 & - & - \\
M_FER_W & 10.0 & 1.94 & 0.98 \\
M_FER_A & 6 & 2.1 & 0.98 \\
M_ZSM5_A & 23 & 1.87 & 0.97 \\
M_ZSM5_W & 25.9 & 2.02 & 0.99 \\
\hline
\end{tabular}

a data from ref. [21,22].

Table 3. Samples acidity via $\mathrm{NH}_{3}$-Temperature Programmed Desorption $\left(\mathrm{NH}_{3}-\mathrm{TPD}\right)$ analysis.

\begin{tabular}{|c|c|c|c|c|c|c|c|c|}
\hline Sample & $\begin{array}{c}\text { Weak Sites } \\
{\left[\mu_{\mathrm{mol}} \mathrm{NH}_{3} / \mathrm{g}_{\text {cat }}\right]^{\mathrm{a}}}\end{array}$ & $\begin{array}{l}X_{i} \\
{[-]}\end{array}$ & $\begin{array}{c}\mathrm{T}^{\mathrm{b}} \\
{\left[{ }^{\circ} \mathrm{C}\right]}\end{array}$ & $\begin{array}{c}\text { Strong Sites } \\
{\left[\mu \mathrm{mol}_{\mathrm{NH} 3} / \mathrm{g}_{\mathrm{cat}}\right]^{\mathrm{a}}}\end{array}$ & $\begin{array}{l}X_{i} \\
{[-]}\end{array}$ & $\begin{array}{c}\mathrm{T}^{\mathrm{c}} \\
{\left[{ }^{\circ} \mathrm{C}\right]}\end{array}$ & $\begin{array}{l}\text { Total Acidity } \\
{\left[\mu \mathrm{mol}_{\mathrm{NH} 3} / \mathrm{g}_{\text {cat }}\right]}\end{array}$ & $\mathbf{R}^{2}$ \\
\hline P_FER & 281 & 0.22 & 272 & 976 & 0.78 & 556 & 1257 & 0.997 \\
\hline P_ZSM5 & 172 & 0.25 & 266 & 513 & 0.75 & 455 & 685 & 0.997 \\
\hline M_FER_W & 184 & 0.40 & 308 & 280 & 0.60 & 398 & 464 & 0.998 \\
\hline M_FER_A ${ }^{d}$ & 229 & 0.60 & 250 & 152 & 0.40 & 500 & 381 & 0.994 \\
\hline M_ZSM55_A & 159 & 0.53 & 275 & 140 & 0.47 & 325 & 299 & 0.998 \\
\hline M_ZSM5_W & 188 & 0.6 & 320 & 129 & 0.40 & 363 & 317 & 0.998 \\
\hline
\end{tabular}

${ }^{a}$ Calculated by $\mathrm{NH}_{3} \mathrm{TPD},{ }^{\mathrm{b}}$ Temperature of desorption of weak acid sites calculated by $\mathrm{NH}_{3}-\mathrm{TPD},{ }^{\mathrm{c}}$ Temperature of desorption of strong acid sites calculated by $\mathrm{NH}_{3}-\mathrm{TPD}$, ${ }^{\mathrm{d}}$ data from ref. [21], $\mathrm{X}_{\mathrm{i}}$ : weak or strong acid sites fraction, $\mathrm{R}^{2}$ correlation factor.

Analysis of hybrid samples shows that the presence of metal leads to a significant reduction in the acidity of both hybrid catalysts compared to the respective parent zeolites [25]. Acid site changes may be caused by both acid site dilution, due to metal addition, and changes in the type and amount of acid sites. In fact, a higher fraction of weak acid sites was calculated for hybrid systems. The generation of weak acid sites, despite the strong acid sites, may be related to a partial ion exchange between $\mathrm{Cu}^{+} / \mathrm{Cu}^{2+}$ ions and zeolite strong Brønsted sites $\left(\mathrm{H}^{+}\right)$during the preparation of the samples. It is interesting to note that this effect is more significant for M_ZSM5_W than for M_ZSM_A, due to the higher solvent capacity of water towards metal precursors, thus favoring ion exchange.

\section{Discussion}

\subsection{Catalytic Test}

Catalytic tests were carried out in the temperature range $180-260^{\circ} \mathrm{C}$, and both methanol conversion and the DME selectivity are reported in the following figures. Figure 2 reports the results for the parent samples and, as expected, the conversion increases with the increase in reaction temperature, reaching its maximum value at $260^{\circ} \mathrm{C}$, while the process selectivity towards the DME, still maintains a good value ( $>0.9)$, confirming the good performances of zeolites in the catalysis of the methanol-to-DME reaction [29].

Interesting results were obtained when investigating the catalytic activity of the hybrid samples as shown in Figure 3. Sample M_ZSM5_W increases its conversion with temperature, until reaching a maximum (0.91) at $240{ }^{\circ} \mathrm{C}$, while selectivity toward DME tends to decrease with the increase in temperature, because, as an effect of the presence of metals, undesired compounds starts to be produced, identified as methyl formate (MF) and dimethoxymethane (DMM) [30]. 


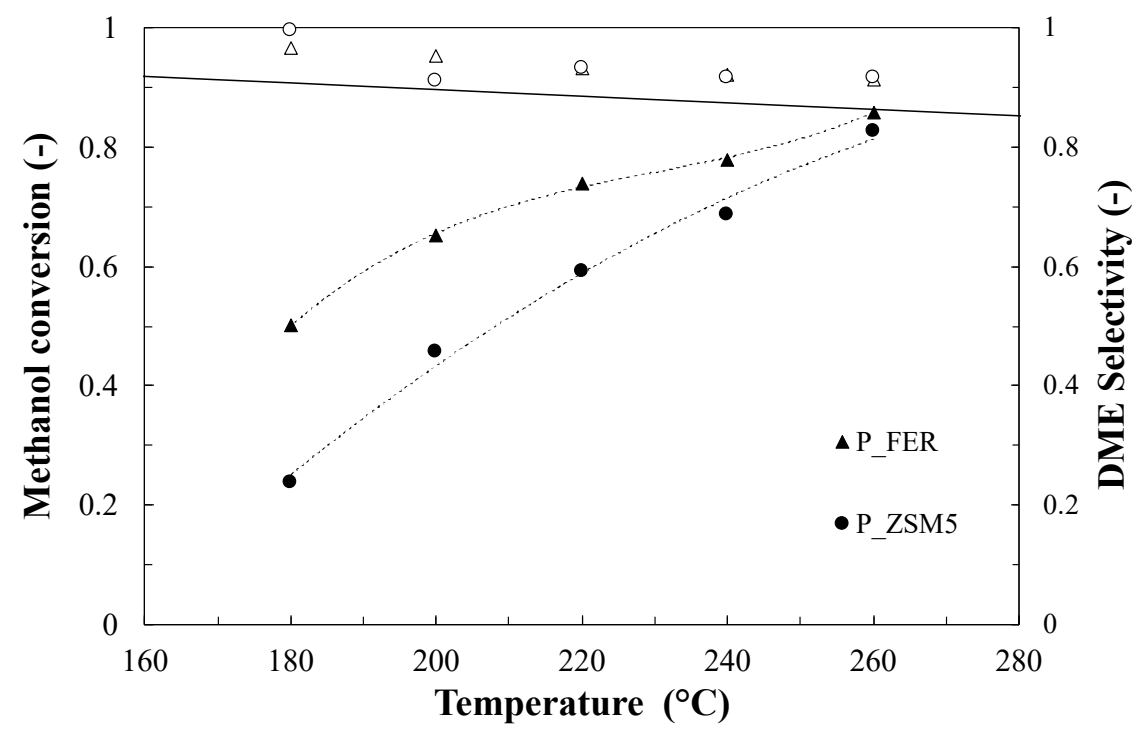

Figure 2. Methanol conversion (closed symbols) and DME selectivity (open symbols) for the parent samples. Test conditions: Methanol $=5.6 \%$; Carrier flow rate $(\mathrm{N} 2)=60 \mathrm{NmL} / \mathrm{min}$; Weight Hourly Space Velocity $\left(\right.$ WHSV) $=4.5 \mathrm{~h}^{-1}$.

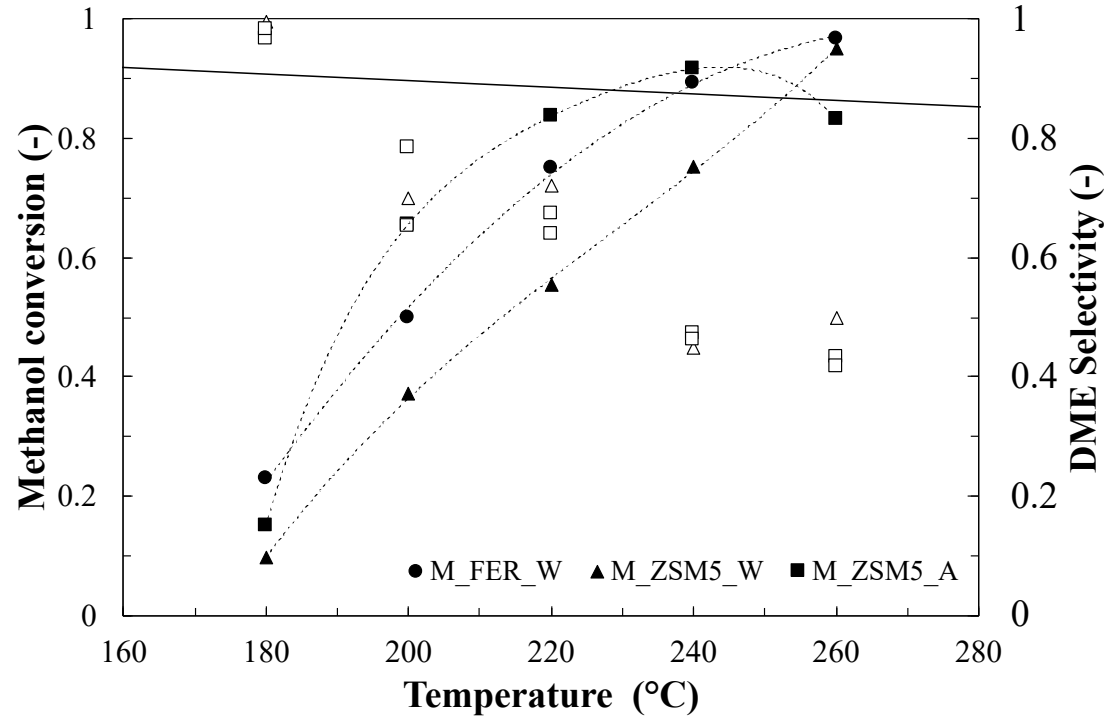

Figure 3. Methanol conversion closed symbols and DME selectivity (open symbols) for hybrid samples. Test conditions: Methanol $=5.6 \%$; Carrier flow rate $(\mathrm{N} 2)=60 \mathrm{NmL} / \mathrm{min}$; WHSV $=4.5 \mathrm{~h}^{-1}$.

Tenner et al. [31] attribute the formation of methyl formate to the dehydrogenation of methanol in the presence of a copper-based catalyst, while the dehydrogenation of methanol to formaldehyde in the presence of a copper-based catalyst and zinc was confirmed [32]. The possible formation of these two compounds has also been suggested by Zhang et al. [33], who, investigating the carbonylation of methanol to dimethyl carbonate in the presence of a Cu-ZSM-5 (prepared by a preparation technique similar that we used for our Cu-MFI catalyst), hypothesized that dimethoxymethane is formed by the interaction of formaldehyde, produced by the partial oxidation of methanol, with the methanol itself, while the methyl formate is formed by the interaction of formic acid, obtained by partial oxidation of the previously formed formaldehyde, with the same alcohol.

It is interesting to note that in our case, we observe the formation of MF and DMM without the presence of oxygen in the reaction mixture. This probably means that $\mathrm{Cu} / \mathrm{Zn}-\mathrm{ZSM} 5$ catalysts (prepared using ethanol as co-precipitation medium) are able to address the reaction to the formation of MF and 
DMM in presence of only water (product of methanol dehydration) without the presence of molecular oxygen (probably due to the lower acidity of this catalyst).

It is important to specify that the equilibrium conversion of Figures 2 and 3 refers to the Methanol-to-DME reaction only; therefore, due to the presence of side and consecutive reactions, the overall measured conversion could easily exceed the reported equilibrium value. The hybrid catalyst made by using the FER structure (M_FER_W) provided conversion exceeding the equilibrium one at $240{ }^{\circ} \mathrm{C}$, with a significant drop in selectivity (around 0.4 ) at the maximum operating temperature. If the effect of solvent is considered, it could be observed that the M_ZSM5_A sample (prepared by using ethanol) shows a higher activity, followed by a rapid decrease above $240{ }^{\circ} \mathrm{C}$, while the selectivity is slightly lower than that of the M_ZSM5_W.

From the catalytic activity data, it was possible to calculate the apparent activation energy of any catalyst (Table 4) with reference to the overall methanol conversion. The parent samples showed very similar values, while differences could be found when considering the hybrid ones. The most relevant difference arises when comparing the hybrid system co-precipitated in water with the samples in ethanol, exhibiting a double value, whatever the used zeolite.

Table 4. Apparent activation energy for methanol conversion. $\mathrm{R}^{2}$ is the correlation factor.

\begin{tabular}{ccc}
\hline Sample & $\begin{array}{c}\mathbf{E}_{\text {app }} \\
{[\mathbf{J} / \mathbf{m o l}]}\end{array}$ & $\begin{array}{c}\mathbf{R}^{\mathbf{2}} \\
{[-]}\end{array}$ \\
\hline P_FER & 18 & 0.967 \\
P_ZSM5 & 21 & 0.984 \\
M_FER_W & 14 & 0.965 \\
M_FER_A & 17 & 0.979 \\
M_ZSM5_A & 17 & 0.946 \\
M_ZSM5_W & 33 & 0.993 \\
\hline
\end{tabular}

\subsection{Duration Test}

Duration tests (Time On Stream, TOS) were carried out at the maximum investigated operating temperature of $260{ }^{\circ} \mathrm{C}$, in order to assess the stability of the catalytic activity. The conversion of methanol and the selectivity towards the DME are shown in Figure 4. The results reveal an excellent catalytic stability of sample P_FER in terms of both methanol conversion and DME selectivity.

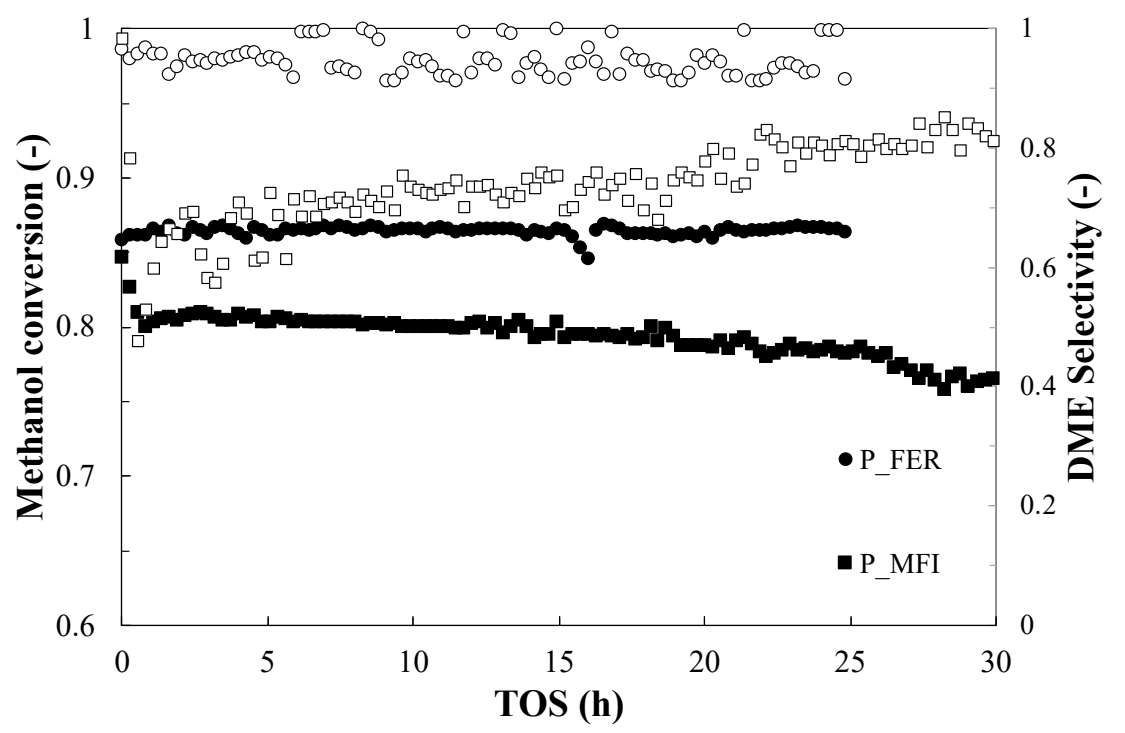

Figure 4. Methanol conversion (closed symbols) and DME selectivity (open symbols) during TOS for the parent samples. Test conditions: $\mathrm{T}=260^{\circ} \mathrm{C}$; Methanol $=5.6 \%$; Carrier flow rate $\left(\mathrm{N}_{2}\right)=60 \mathrm{NmL} / \mathrm{min}$; $\mathrm{WHSV}=2.3 \mathrm{~h}^{-1}$. 
An appreciable conversion drop from 0.85 to 0.80 is observed for P_ZSM5 during the first hour of time-on-stream test. Afterwards, the sample exhibits a high stability with a very slow deactivation trend during the test. These results are in accordance with what is provided in the literature [19], as the observed initial deactivation is related to coke deposition. In a previously study, the authors observed that coke deposition mainly occurs in the early hours of time-on-stream tests, thus causing activity loss during this period [34]. Instead, interesting results are found with hybrid systems (Figure 5), such as for the sample prepared with ethanol as co-precipitation medium (M_ZSM5_A), where the conversion of methanol dropped from 0.92 to 0.2 after only $14 \mathrm{~h}$ of reaction, and selectivity decreased with the progress of the reaction, reaching values close to 0.2 , due to the extent of side reactions. On the contrary, the sample of ZSM5 prepared with water, despite the same drop in conversion, exhibited higher and more consistent selectivity. The same trend of conversion and stable selectivity was also observed for the M_FER_W, and it could be possible that the co-precipitation medium plays a role in the metal catalyst activity. On the other hand, since the selectivity of every sample was significantly lower than 1, different reaction pathways are expected to take place in this system. To verify this option, the productivity of methyl formate (FM) and dimethoxymethane (DMM) was also monitored during TOS via GC-MS technique.

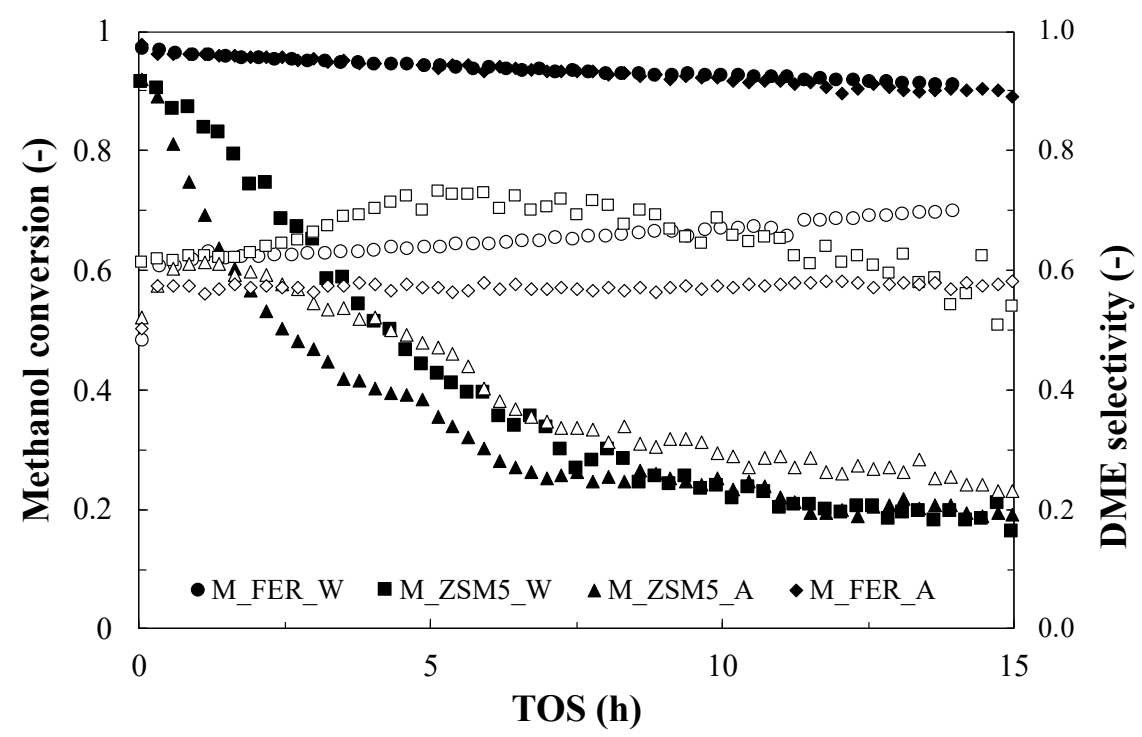

Figure 5. Methanol conversion (closed symbols) and DME selectivity (open symbols) during TOS for the hybrid samples. Test conditions: $\mathrm{T}=260{ }^{\circ} \mathrm{C}$; Methanol $=5.6 \%$; Carrier flow rate $\left(\mathrm{N}_{2}\right)=60 \mathrm{NmL} / \mathrm{min}$; $\mathrm{WHSV}=2.3 \mathrm{~h}^{-1}$.

No appreciable signal for those two compounds was found for M_FER_W, M_FER_A and M_ZSM5_W, while data for M_ZSM5_A (Figure 6) clearly indicates an increase in the presence of such compounds. Therefore, it could be observed that the formation of such products is mainly determined by the zeolite structure.

Both DMM and FM selectivity increase with time. This trend may be related to a progressive change of metal phase from metallic $\mathrm{Cu}$ to $\mathrm{Cu} 2 \mathrm{O}$ species, promoting $\mathrm{FM}$ and DMM formation [35]. To check this evidence, the ratio $\mathrm{H}_{2} / \mathrm{CO}_{2}$ was also monitored, and the results are reported in Figure 7 . It clearly appears that this ratio strongly depends on the catalyst type: in the case of M_FER_W and M_ZSM5_A, the value remains around 3, an indication of the preferential complete dehydrogenation of methanol in this catalyst. On the contrary, when the M_ZSM5_W catalyst is considered, the ratio diverges from the value of 3 , indicating that another reaction pathway is taking place, involving the formation of FM and DMM and the preferential production of hydrogen with respect to carbon dioxide, even though the occurrence of hydrogen generation via methanol steam reforming in these operating conditions cannot be excluded [36,37]. 


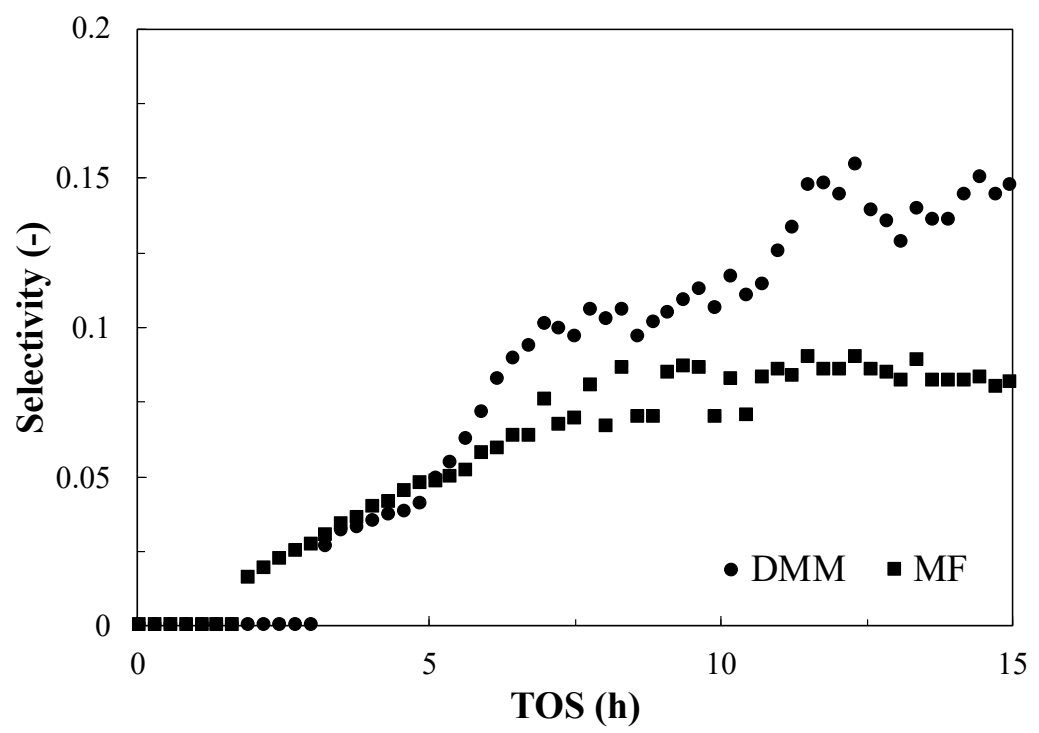

Figure 6. Selectivity toward methyl formate (MF) and dimethoxymethane (DMM) during TOS of the M_ZSM5_A. No appreciable MF and DMM was detected for the other investigated hybrid catalysts.

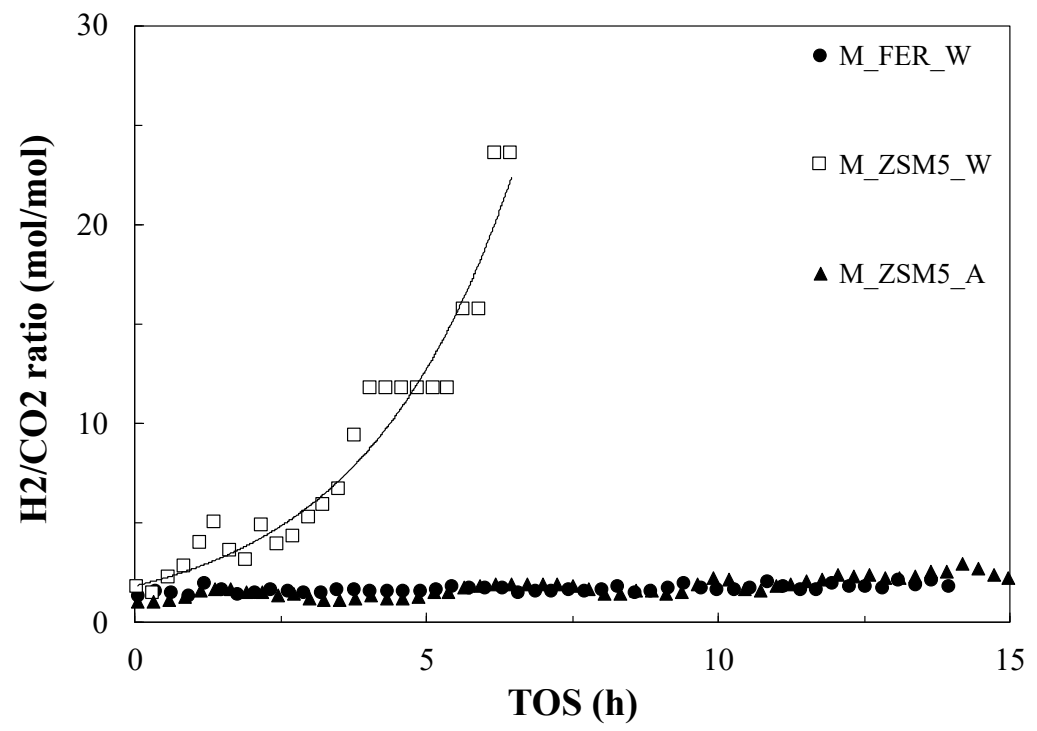

Figure 7. $\mathrm{H}_{2} / \mathrm{CO}_{2}$ ratio measured during TOS test.

This evidence is in good agreement with a recently proposed mechanism [30] leading to DMM formation via non-oxidative dehydrogenation of methanol through formaldehyde intermediate followed by acetalization reaction, producing hydrogen and water (no carbon oxides) as side products, even though direct methanol oxidation cannot be excluded. This reaction pathway was clearly demonstrated for methanol in liquid phase, while no appreciable yield of DMM, as in our case, was obtained when the reaction was conducted in gas phase, since methanol dehydrogenation takes place appreciably at very high temperatures (above $500{ }^{\circ} \mathrm{C}$ ), while acetalization requires milder conditions $\left(300^{\circ} \mathrm{C}\right)$.

\section{Materials and Methods}

\subsection{Physicochemical Characterization}

The crystallinity of the samples was analyzed by X-ray powder diffraction spectroscopy $(\mathrm{Cu} \mathrm{K} \alpha$ radiation, $\lambda=1.5406,40 \mathrm{kV}, 30 \mathrm{~mA}, 5-50^{\circ} 2 \theta$ range) (APD 2000, GNR Analytical Instruments, Agrate Conturbia, NO, Italy). 
Porosimetric analysis was carried out by nitrogen adsorption/desorption isotherms at $-196^{\circ} \mathrm{C}$ (ASAP 2020, Micromeritics Instruments Corporation, Norcross, GA, USA) [27]. The specific surface area and the volume of micropores and/or mesopores were estimated by BET and t-plot methods, respectively.

The chemical composition of the investigated catalysts was measured via Atomic Adsorption analysis (GBC 932 AA), while their morphology was observed by a SEM (MIRA, Tescan, Brno, Czech Republic), at 6.6.10-6 torr vacuum conditions, with a current of $15 \mathrm{kV}$.

The concentration of the acid sites was measured by $\mathrm{NH}_{3}$-Temperature Programmed Desorption ( $\mathrm{NH}_{3}$-TPD) (TPDRO1100, ThermoFisher, Waltham, MA, USA.), whose procedure has already been published [27].

\subsection{Catalytic Tests}

The catalytic activity of the samples was investigated in an experimental apparatus described elsewhere [8] in the temperature range $180-260^{\circ} \mathrm{C}$ and with a Weight Hourly Space Velocity (WHSV) of $2.3 \mathrm{~g}_{\mathrm{MetOH}} /\left(\mathrm{g}_{\mathrm{cat}} \mathrm{h}\right)$. To assess the catalyst stability, Time-On-Stream tests were carried out at $260{ }^{\circ} \mathrm{C}$ for $20 \mathrm{~h}$, loading $140 \mathrm{mg}$ of catalysts (pellets size: $300-500 \mu \mathrm{m}$ ) for each run. Before each test, the catalyst sample was dried under nitrogen flow at $240{ }^{\circ} \mathrm{C}$ for $3 \mathrm{~h}$ and the product stream composition was analyzed by gas chromatography (7890A, Agilent Technologies, Santa Clara, CA, USA.). A specific capillary column, J\&W 125-1032, and a Flame Ionization Detector (FID) were used to detect methanol, hydrocarbons and other organics [8]. Both $\mathrm{H}_{2}$ and $\mathrm{CO}_{2}$ were analyzed using the same GC instrument equipped with a PoraPlotQ column flushed with argon and a thermal conductivity detector kept at $250 \pm 0.1^{\circ} \mathrm{C}$. Experimental results are presented in terms of methanol molar conversion and DME selectivity, defined as it follows:

$$
\begin{gathered}
\text { MetOH conversion }=\frac{\text { converted } \mathrm{MetOH}\left(\mathrm{gmol}^{\mathrm{min}} \mathrm{mi}^{-1}\right)}{\text { feed } \mathrm{MetOH}\left(\mathrm{gmol} \cdot \mathrm{min}^{-1}\right)} \\
D M E \text { selectivity }=\frac{2 \text { DME outstream }\left(\mathrm{gmol} \cdot \mathrm{min}^{-1}\right)}{\text { converted } \mathrm{MetOH}\left(\mathrm{gmol} \cdot \mathrm{min}^{-1}\right)}
\end{gathered}
$$

\section{Conclusions}

The MFI and FER zeolites were tested in the dehydration reaction of methanol to dimethyl ether in the presence of metal compounds CuZnZr, in order to determine the effect of this phase on methanol conversion and selectivity towards DME. Hybrid systems were prepared using gel oxalate coprecipitation, which involves the co-precipitation of metals on the acid catalyst, previously dissolved in a solution with oxalic acid. To additionally investigate the role of the co-precipitation medium, two routes were followed using ethanol or distilled water as a co-precipitation medium. In fact, the catalytic tests show a clear deactivation of the hybrid systems in which the acid catalyst has an MFI structure, while this effect was not observed in systems prepared with FER. This result appears interesting, because the MFI did not show deactivation when tested individually. The reported evidence suggests that the metal/zeolite interaction varies according to the morphology of the zeolitic structure: three-dimensional in the case of MFI, two-dimensional in the case of FER. This data is reflected in what has been attributed in the literature $[38,39]$ to the deactivation of the zeolite to the migration of the atoms of $\mathrm{Cu}^{2+}$ and $\mathrm{Zn}^{2+}$ on the acidic sites and in the pores of the latter, in synergy with the possible sintering of metal particles, promoted by the water produced by the dehydration of methanol to DME. The hybrid systems showed other substantial differences in the formation of secondary products, mainly methyl-formate and dimethoxymethane, which significantly reduce the selectivity of the process towards the desired product. It also seems that the presence of this by-product could depend on the co-precipitation medium as well as on the topology of the zeolite used. The structural properties, analyzed by means of porosimetric tests, also highlighted the formation of mesoporosity in all the co-precipitated samples, which was attributed to the deposition of the metals 
on the zeolite and accentuated in particular in the samples with respect to the FER-prepared one, allowing us to hypothesize a possible link between this and the presence of MF and DMM in the reaction products. Finally, a particularly interesting finding was found in the tests carried out on the two hybrid catalysts prepared by co-precipitation on an MFI zeolite. In fact, the results show that the formation of methyl-formate and dimethoxymethane takes place exclusively on the M_MFI_A hybrid system prepared using ethanol as a co-precipitation medium, while there are no traces in the test carried out on the co-precipitated sample using distilled water. This evidence is in agreement with a non-oxidative reaction pathway for DMM production from methanol. As a main conclusion, the results highlighted the existence of a potential shape selectivity of hybrid systems based on FER with respect to secondary products, but at the same time the presence of a relationship between the co-precipitation medium and the process selectivity towards dimethyl ether.

Supplementary Materials: The following are available online at http://www.mdpi.com/2073-4344/10/6/671/s1; Figure S1: XRD patterns for the parent and hybrid samples. The main metallic phases detected are: metallic copper $(+)$, cuprite $(*)$, tenorite (\#) and zincite (§); Figure S2: Nitrogen adsorption (closed symbols) and desorption (open symbols) isotherms at 77K for hybrid samples; Figure S3: Pore size distribution for hybrid samples; Figure S4: NH3-TPD data and deconvolution curves for all the investigated samples.

Author Contributions: Conceptualization, E.C. and M.M.; methodology, E.C.; investigation, A.C.; resources, G.G.; data curation, A.C. and F.D.; writing-original draft preparation, F.D.; writing-review and editing, M.M., E.C., G.G.; supervision, G.G.; All authors have read and agreed to the published version of the manuscript.

Funding: This research was funded by Italian Ministry of Education, University and Research, Project Name "CO2ONLY", grant code PRIN2017- 2017WR2LRS.

Conflicts of Interest: The authors declare no conflict of interest.

\section{References}

1. Fleisch, T.; Basu, A.; Sills, R. Introduction and advancement of a new clean global fuel: The status of DME developments in China and beyond. J. Nat. Gas Sci. Eng. 2012, 9, 94-107. [CrossRef]

2. Fleisch, T.; McCarthy, C.; Basu, A.; Udovich, C.; Charbonneau, P.; Slodowske, W.; Mikkelsen, S.-E.; McCandless, J. A New Clean Diesel Technology: Demonstration of ULEV Emissions on a Navistar Diesel Engine Fueled with Dimethyl Ether. SAE Tech. Pap. Ser. 1995. [CrossRef]

3. Catizzone, E.; Migliori, M.; Purita, A.; Giordano, G. Ferrierite vs. $\gamma-\mathrm{Al}_{2} \mathrm{O}_{3}$ : The superiority of zeolites in terms of water-resistance in vapour-phase dehydration of methanol to dimethyl ether. J. Energy Chem. 2019, 30, 162-169. [CrossRef]

4. Bonura, G.; Cordaro, M.; Spadaro, L.; Cannilla, C.; Arena, F.; Frusteri, F. Hybrid Cu-ZnO-ZrO $2 / \mathrm{H}_{-}-\mathrm{ZSM}_{5}$ system for the direct synthesis of DME by $\mathrm{CO}_{2}$ hydrogenation. Appl. Catal. B Environ. 2013, 140, 16-24. [CrossRef]

5. Centi, G.; Perathoner, S.; Pino, F.; Arrigo, R.; Giordano, G.; Katovic, A.; Pedulà, V. Performances of Fe-[Al, B]MFI catalysts in benzene hydroxylation with $\mathrm{N}_{2} \mathrm{O}$. Catal. Today 2005, 110, 211-220. [CrossRef]

6. Katovic, A.; Giordano, G.; Bonelli, B.; Onida, B.; Garrone, E.; Lentz, P.; Nagy, J.B. Preparation and characterization of mesoporous molecular sives containing Al, Fe or Zn. Microporous Mesoporous Mater. 2001, 44, 275-281. [CrossRef]

7. Kattel, S.; Ramírez, P.J.; Chen, J.G.; Rodriguez, J.A.; Liu, P. Active sites for $\mathrm{CO}_{2}$ hydrogenation to methanol on $\mathrm{Cu} / \mathrm{ZnO}$ catalysts. Science 2017, 355, 1296-1299. [CrossRef]

8. Migliori, M.; Aloise, A.; Catizzone, E.; Giordano, G. Kinetic Analysis of Methanol to Dimethyl Ether Reaction over H-MFI Catalyst. Ind. Eng. Chem. Res. 2014, 53, 14885-14891. [CrossRef]

9. Hong, Z.-S.; Cao, Y.; Deng, J.-F.; Fan, K. CO $\mathrm{CO}_{2}$ Hydrogenation to Methanol Over $\mathrm{Cu} / \mathrm{ZnO} / \mathrm{Al}_{2} \mathrm{O}_{3}$ Catalysts Prepared by a Novel Gel-Network-Coprecipitation Method. Catal. Lett. 2002, 82, 37-44. [CrossRef]

10. Liang, X.-L.; Dong, X.; Lin, G.-D.; Zhang, H.-B. Carbon nanotube-supported Pd-ZnO catalyst for hydrogenation of $\mathrm{CO}_{2}$ to methanol. Appl. Catal. B Environ. 2009, 88, 315-322. [CrossRef]

11. Xu, J.; Su, X.; Liu, X.; Pan, X.; Pei, G.; Huang, Y.; Wang, X.; Zhang, T.; Geng, H. Methanol synthesis from $\mathrm{CO}_{2}$ and $\mathrm{H}_{2}$ over $\mathrm{Pd} / \mathrm{ZnO} / \mathrm{Al}_{2} \mathrm{O}_{3}$ : Catalyst structure dependence of methanol selectivity. Appl. Catal. A Gen. 2016, 514, 51-59. [CrossRef] 
12. Jiang, X.; Koizumi, N.; Guo, X.; Song, C. Bimetallic Pd-Cu catalysts for selective $\mathrm{CO}_{2}$ hydrogenation to methanol. Appl. Catal. B Environ. 2015, 170, 173-185. [CrossRef]

13. Jadhav, S.G.; Vaidya, P.D.; Bhanage, B.M.; Joshi, J.B. Catalytic carbon dioxide hydrogenation to methanol: A review of recent studies. Chem. Eng. Res. Des. 2014, 92, 2557-2567. [CrossRef]

14. Schumann, J.; Tarasov, A.V.; Thomas, N.; Schlögl, R.; Behrens, M. Cu,Zn-based catalysts for methanol synthesis: On the effect of calcination conditions and the part of residual carbonates. Appl. Catal. A Gen. 2016, 516, 117-126. [CrossRef]

15. Bonura, G.; Arena, F.; Mezzatesta, G.; Cannilla, C.; Spadaro, L.; Frusteri, L. Role of the ceria promoter and carrier on the functionality of $\mathrm{Cu}$-based catalysts in the $\mathrm{CO}_{2}$-to-methanol hydrogenation reaction. Catal. Today 2011, 171, 251-256. [CrossRef]

16. Wang, G.; Zuo, Y.; Han, M.; Wang, J. Copper crystallite size and methanol synthesis catalytic property of Cu-based catalysts promoted by Al, Zr and Mn. React. Kinet. Mech. Catal. 2010, 101, 443-454. [CrossRef]

17. Ladera, R.; Pérez-Alonso, F.J.; Carballo, J.M.G.; Ojeda, M.; Rojas, S.; Fierro, J.L.G. Catalytic valorization of $\mathrm{CO}_{2}$ via methanol synthesis with Ga-promoted $\mathrm{Cu}-\mathrm{ZnO}-\mathrm{ZrO}_{2}$ catalysts. Appl. Catal. B Environ. 2013, 142, 241-248. [CrossRef]

18. Catizzone, E.; Van Daele, S.; Bianco, M.; Di Michele, A.; Aloise, A.; Migliori, M.; Valtchev, V.; Giordano, G. Catalytic application of ferrierite nanocrystals in vapour-phase dehydration of methanol to dimethyl ether. Appl. Catal. B Environ. 2019, 243, 273-282. [CrossRef]

19. Migliori, M.; Catizzone, E.; Aloise, A.; Bonura, G.; Gómez-Hortigüela, L.; Frusteri, L.; Cannilla, C.; Frusteri, F.; Giordano, G. New insights about coke deposition in methanol-to-DME reaction over MOR-, MFI- and FER-type zeolites. J. Ind. Eng. Chem. 2018, 68, 196-208. [CrossRef]

20. Frusteri, F.; Bonura, G.; Cannilla, C.; Ferrante, G.D.; Aloise, A.; Catizzone, E.; Migliori, M.; Giordano, G. Stepwise tuning of metal-oxide and acid sites of CuZnZr-MFI hybrid catalysts for the direct DME synthesis by CO2 hydrogenation. Appl. Catal. B Environ. 2015, 176, 522-531. [CrossRef]

21. Bonura, G.; Cannilla, C.; Frusteri, L.; Catizzone, E.; Todaro, S.; Migliori, M.; Giordano, G.; Frusteri, F. Interaction effects between $\mathrm{CuO}-\mathrm{ZnO}-\mathrm{ZrO}_{2}$ methanol phase and zeolite surface affecting stability of hybrid systems during one-step $\mathrm{CO}_{2}$ hydrogenation to DME. Catal. Today 2020, 345, 175-182. [CrossRef]

22. Frusteri, F.; Migliori, M.; Cannilla, C.; Frusteri, L.; Catizzone, E.; Aloise, A.; Giordano, G.; Bonura, G. Direct $\mathrm{CO}_{2}$-to-DME hydrogenation reaction: New evidences of a superior behaviour of FER-based hybrid systems to obtain high DME yield. J. CO2 Util. 2017, 18, 353-361. [CrossRef]

23. Catizzone, E.; Bonura, G.; Migliori, M.; Frusteri, F.; Giordano, G. $\mathrm{CO}_{2}$ recycling to dimethyl ether: State-of-the-art and perspectives. Molecules 2018, 23, 21. [CrossRef] [PubMed]

24. Bonura, G.; Frusteri, F.; Cannilla, C.; Drago Ferrante, G.; Aloise, A.; Catizzone, E.; Migliori, M.; Giordano, G. Catalytic features of $\mathrm{CuZnZr-zeolite} \mathrm{hybrid} \mathrm{systems} \mathrm{for} \mathrm{the} \mathrm{direct} \mathrm{CO}_{2}$-to-DME hydrogenation reaction. Catal. Today 2016, 277, 45-54. [CrossRef]

25. Bonura, G.; Migliori, M.; Frusteri, L.; Cannilla, C.; Catizzone, E.; Giordano, G.; Frusteri, F. Acidity control of zeolite functionality on activity and stability of hybrid catalysts during DME production via $\mathrm{CO}_{2}$ hydrogenation. J. $\mathrm{CO}_{2}$ Util. 2018, 24, 398-406. [CrossRef]

26. Miletto, I.; Catizzone, E.; Bonura, G.; Ivaldi, C.; Migliori, M.; Gianotti, E.; Marchese, L.; Frusteri, F.; Giordano, G. In situ FT-IR characterization of $\mathrm{CuZnZr/ferrierite} \mathrm{hybrid} \mathrm{catalysts} \mathrm{for} \mathrm{one-pot} \mathrm{CO}_{2}$-to-DME conversion. Materials 2018, 11, 2275. [CrossRef]

27. Catizzone, E.; Aloise, A.; Migliori, M.; Giordano, G. The effect of FER zeolite acid sites in methanol-to-dimethyl-ether catalytic dehydration. J. Energy Chem. 2017, 26, 406-415. [CrossRef]

28. Chen, X.; Todorova, T.; Vimont, A.; Ruaux, V.; Qin, Z.; Gilson, J.-P.; Valtchev, V. In situ and post-synthesis control of physicochemical properties of FER-type crystals. Microporous Mesoporous Mater. 2014, 200, 334-342. [CrossRef]

29. Catizzone, E.; Aloise, A.; Migliori, M.; Giordano, G. From 1-D to 3-D zeolite structures: Performance assessment in catalysis of vapour-phase methanol dehydration to DME. Microporous Mesoporous Mater. 2017, 243, 102-111. [CrossRef]

30. Sun, R.; Delidovich, I.; Palkovits, R. Dimethoxymethane as a Cleaner Synthetic Fuel: Synthetic Methods, Catalysts, and Reaction Mechanism. ACS Catal. 2019, 9, 1298-1318. [CrossRef]

31. Tonner, S.P.; Trimm, D.L.; Wainwright, M.S.; Cant, N.W. Dehydrogenation of methanol to methyl formate over copper catalysts. Ind. Eng. Chem. Prod. Res. Dev. 1984, 23, 384-388. [CrossRef] 
32. Zhang, Y.; Shi, F.; Fan, X.; Tierney, J.; Wender, I. Coproduction of hydrogen and methyl formate by dehydrogenation of methanol. In Proceedings of the 23rd Annual International Pittsburgh Coal Conference, PCC-Coal-Energy, Environment and Sustainable Development, Cape Town, South Africa, 8-12 August 2006.

33. Zhang, Y.; Drake, I.J.; Briggs, D.N.; Bell, A.T. Synthesis of dimethyl carbonate and dimethoxy methane over Cu-ZSM-5. J. Catal. 2006, 244, 219-229. [CrossRef]

34. Catizzone, E.; Aloise, A.; Migliori, M.; Giordano, G. Dimethyl ether synthesis via methanol dehydration: Effect of zeolite structure. Appl. Catal. A Gen. 2015, 502, 215-220. [CrossRef]

35. Wu, L.; Li, B.; Zhao, C. Direct Synthesis of Hydrogen and Dimethoxylmethane from Methanol on Copper/Silica Catalysts with Optimal $\mathrm{Cu}^{+} / \mathrm{Cu} 0$ Sites. ChemCatChem 2018, 10, 1140-1147. [CrossRef]

36. Matter, P.; Ozkan, U.S. Effect of pretreatment conditions on $\mathrm{Cu} / \mathrm{Zn} / \mathrm{Zr}$-based catalysts for the steam reforming of methanol to $\mathrm{H}_{2}$. J. Catal. 2005, 234, 463-475. [CrossRef]

37. Yao, C.-Z.; Wang, L.-C.; Liu, Y.-M.; Wu, G.-S.; Cao, Y.; Dai, W.-L.; He, H.-Y.; Fan, K.-N. Effect of preparation method on the hydrogen production from methanol steam reforming over binary $\mathrm{Cu} / \mathrm{ZrO}$ catalysts. Appl. Catal. A Gen. 2006, 297, 151-158. [CrossRef]

38. Ordomsky, V.V.; Cai, M.; Sushkevich, V.; Moldovan, S.; Ersen, O.; Lancelot, C.; Valtchev, V.; Khodakov, A.Y. The role of external acid sites of ZSM-5 in deactivation of hybrid CuZnAl/ZSM- 5 catalyst for direct dimethyl ether synthesis from syngas. Appl. Catal. A Gen. 2014, 486, 266-275. [CrossRef]

39. García-Trenco, A.; Martinez, A. The influence of zeolite surface-aluminum species on the deactivation of $\mathrm{CuZnAl} /$ zeolite hybrid catalysts for the direct DME synthesis. Catal. Today 2014, 227, 144-153. [CrossRef]

(C) 2020 by the authors. Licensee MDPI, Basel, Switzerland. This article is an open access article distributed under the terms and conditions of the Creative Commons Attribution (CC BY) license (http://creativecommons.org/licenses/by/4.0/). 